\title{
IUFOST2006/1189 European Technology Platform Food for Life
}

\author{
J. Maat \\ UNILEVER RESEARCH \& DEVELOPMENT VLAARDINGEN, P.O BOX 114, 3130 AC \\ VLAARDINGEN, Netherlands \\ jan.maat@unilever.com
}

The agro-food sector The food and drink industries alone had a turnover of 840 billion e in 2005, transforming over $70 \%$ of Europe's agricultural raw materials. The sector employs over 4.1 million people, the majority in SMEs which are the engine for economic growth, job creation and national and regional development. However, in 2003 the sector invested only $0.3 \%$ in R\&D, much less than its global competitors and well below the average across European manufacturing sectors.

ETP Food for Life ETP Food for Life was initiated in November 2004 specifically to unite stakeholders in a common long-term programme of research, communication, training and technology transfer with the aim of stimulating innovation, enhancing the global competitiveness of European industry and exerting a positive impact on the health and well-being of European consumers.

The ETP Food for Life Vision Document was published in July 2005 [http://etp.ciaa.be], following which expert groups of academics and representatives of industry and consumer bodies were established to identify the major challenges to innovation in the agro-food sector. Following consultation, the resulting Stakeholders' Proposal for a Strategic Research Agenda [SSRA] is now posted at http://etp.ciaa.be, where it will form the basis of extensive national-, regional- and website consultations.

The research challenges The SSRA identifies seven trans-disciplinary challenges deemed necessary to stimulate or underpin innovation. These are:

o Ensuring that the healthy choice is the easy choice for consumers, o Delivering a healthy diet, o Developing value-added food products with superior quality, convenience, availability and affordability, o Assuring safe foods that consumers can trust, o Achieving sustainable food production, o Managing the food chain, and o Communication, Training and Technology Transfer.

Complementary activities that will deliver innovation are also identified: these include increasing the financial resources at European and national level that are committed to innovation of the food chain, improving education, skills and facilities in Europe, optimizing stakeholder understanding and engagement, and initiate scenario studies to identify and address future challenges and opportunities.

Next steps Consultation on the SSRA will last until early next year and a definitive Strategic Research Agenda and Implementation Plan will be published in March 2007 detailing the research, training and communication activities crucial for enhanced innovation together with a strategy for their management and funding.

ETP Food for Life will closely interact with other ETPs addressing food, biotechnology and agriculture, most notably ETP Plants for the Future, and will support national food platforms to underpin its activities and ensure that it addresses the needs and opportunities of all of Europe. 